\title{
Identification: The missing link between joint attention and imitation?
}

\author{
JESSICA A. HOBSON AND R. PETER HOBSON \\ University College London
}

\begin{abstract}
In this paper we outline our hypothesis that human intersubjective engagement entails identifying with other people. We tested a prediction derived from this hypothesis that concerned the relation between a component of joint attention and a specific form of imitation. The empirical investigation involved "blind" ratings of videotapes from a recent study in which we tested matched children with and without autism for their propensity to imitate the self-/other-orientated aspects of another person's actions. The results were in keeping with three a priori predictions, as follows: (a) children with autism contrasted with control participants in spending more time looking at the objects acted upon and less time looking at the tester; (b) participants with autism showed fewer "sharing" looks toward the tester, and although they also showed fewer "checking" and "orientating" looks, they were specifically less likely to show any sharing looks; and, critically, (c) within each group, individual differences in sharing looks (only) were associated with imitation of self-other orientation. We suggest that the propensity to adopt the bodily anchored psychological stance of another person is essential to certain forms of joint attention and imitation, and that a weak tendency to identify with others is pivotal for the developmental psychopathology of autism.
\end{abstract}

The discipline of developmental psychopathology represents a uniquely powerful investigative approach for identifying the mechanisms as well as the course of human psychological development (Cicchetti, 1993; Sroufe \& Rutter, 1984). One reason for this is that, through the study of typical vis-à-vis atypical

This research was supported by the Economic and Social Research Council (award reference R000239355), the Baily Thomas Charitable Foundation, and the Tavistock Clinic, London (with NHS R\&D funding). The manuscript was completed while the authors were at the Center for Advanced Study in the Behavioral Sciences, Stanford. We are grateful to the staff, students, and parents at Edith Borthwick School, Helen Allison School, Springhallow School, and Swiss Cottage School for their generous involvement in this project; Dave Williams, Valentina Levi, and Susana Caló for their assistance with ratings of joint attention; and Tony Lee and Rosa García Pérez for their many contributions to the research.

Address correspondence and reprint requests to: Jessica A. Hobson, Institute of Child Health and Tavistock Clinic, University College London, 120 Belsize Lane, London NW3 5BA, UK; E-mail: jessica.meyer@ucl.ac.uk. developmental pathways, it is possible to discern associations and dissociations among aspects of social and cognitive functioning that are otherwise difficult to disengage from one another. The present paper presents an empirical study of two seemingly distinct socialcognitive propensities among children with and without autism - engaging in "sharing" forms of joint attention, and imitating self-/otherorientated aspects of other people's actionsthat, according to our hypothesis, are underpinned by a common, intersubjective process. This is the process of identifying with someone else. In identification, an observer registers and assimilates another person's bodily anchored psychological stance (whether in feeling or action or some other way of relating to the world), in such a way that the stance becomes a potential way of the observer relating to the world from his or her own position. We believe that this propensity determines uniquely human forms of sharing and intersubjective communication and role taking (Hobson, 2002/2004). 


\section{Joint Attention and Imitation in Early Typical Development}

At the end of the first year of life, perhaps building upon earlier forms of dyadic social engagement (Hobson, Patrick, Crandell, García-Pérez, \& Lee, 2004; Striano \& Rochat, 1999), infants engage in new forms of social exchange involving shared or coordinated actions and attitudes toward the world (e.g., Bakeman \& Adamson, 1984; Klinnert, 1984; Moses, Baldwin, Rosicky, \& Tidball, 2001; Sorce, Emde, Campos, \& Klinnert, 1985; Trevarthen \& Hubley, 1978). In social interchanges grouped under the heading of "joint attention" (Seibert, Hogan, \& Mundy, 1982), they monitor and follow the gaze of another person (responding to joint attention [RJA]) and point to, show, and/or alternate eye contact with reference to object and events (initiating joint attention [IJA]) to direct a person's attention, share experiences, request things, or inform. Among typically developing infants, positive affect is associated more with sharing experiences in joint attention than with instrumental gaze following or requesting (Kasari, Sigman, Mundy, \& Yirmiya, 1990; Mundy, Kasari, \& Sigman, 1992; also Adamson \& Bakeman, 1985; Bruner, 1981; Rheingold, Hay, \& West, 1976). Thus, sometimes but not always, joint attention serves as both the means to and expression of sharing experiences of the world with others, where sharing entails intersubjective contact and emotional connectedness between people (Hobson, 1989, 1993).

From very early in life, infants also show the ability to imitate, for example, translating what they see in other people's faces to their own facial expressions (Field, Woodson, Greenberg, \& Cohen, 1982; Kugiamutsakis, 1998; Meltzoff \& Moore, 1997). Beginning around 9 months of age, they copy simple novel actions involving objects (Meltzoff, 1988; Meltzoff \& Moore, 1998b) and may be observed to reenact something of the style as well as content of adult activities and copy self-/other-orientated actions. In waving goodbye, for example, or in feeding an adult with a spoon (Bråten, 1998), the child shows role reversal and responds in kind to the actions shown toward the self by someone else (also Hobson, 1993; Tomasello, 1999). One way of describing such events is to say that the child identifies with the person who waves or feeds, so that waving goodbye to the other, or feeding the other, is not only perceived but also assimilated into the child's own repertoire of actions.

There is only a modest research literature on the relation between joint attention and imitation in early typical development, and results thus far are not entirely consistent. Carpenter, Nagell, and Tomasello (1998) studied 24 infants between 9 and 15 months of age, and reported correlations among the ages of emergence of several social-cognitive abilities, including aspects of joint attention and imitation of instrumental and arbitrary goaldirected actions. In contrast, in a cross-sectional study of 60 infants between 8 and 14 months, Slaughter and McConnell (2003) found no relation between performance in imitating actions on objects and gaze following or social referencing. Charman et al. (2000) reported that among typically developing 20-monthold infants, the tendency to alternate gaze between activated mechanical toys and an adult was related to imitation of actions upon objects, once variance associated with IQ had been taken into account. A further study of a different kind was one prompt for us to conduct the present investigation. Carpenter, Tomasello, and Savage-Rumbaugh (1995) reported a positive relation between joint attention skills and imitative learning in young typically developing children and nonhuman primates. Compared with chimpanzees, children spent about twice as much time looking at the tester's face, and in each group, joint attention in the form of coordinated looks between the object and partner was associated with the propensity to imitate actions. In their discussion, Carpenter et al. (1995) speculated that differentiating between looks to the tester for purposes of sharing experiences, as opposed to looks for checking out the situation or orientating to her sounds or actions, may have been especially important, but these forms of looking were not measured as the investigators opted for what they considered to be a more objective behavioral coding approach. 


\section{The Case of Autism}

Kanner (1943) described children with autism as having a basic impairment in the ability to engage in "affective contact" with others. In the late 1980s, more elaborated theoretical accounts of the development of cognitive as well as social features of autism emerged with a focus on deficits in affective coordination and nonverbal communication with others as central to the disorder (Hobson, 1989, 1993; Mundy \& Sigman, 1989). Over the past two decades, systematic investigations have revealed how the children show disturbances in their ability to direct expressions of affect to another person, use facial expressions communicatively, and resonate to the emotions and bodily expressions of others (Bacon, Fein, Morris, Waterhouse, \& Allen, 1998; Charman et al., 1997; Dawson, Hill, Spencer, Galpert, \& Watson, 1990; Hobson \& Lee, 1998; Landry \& Loveland, 1988; Reddy, Williams, \& Vaughan, 2002; Sigman, Kasari, Kwon, \& Yirmiya, 1992; Wetherby \& Prutting, 1984). The children's lesser tendency to look toward others, not only in frequency but also in intensity of eye contact, is characteristic, and probably an early marker of the syndrome (e.g., Dawson, Osterling, Meltzoff, \& Kuhl, 2000; DiLavore, Lord, \& Rutter, 1995; Volkmar \& Mayes, 1990; Wimpory, Hobson, Williams, \& Nash, 2000). In the domain of joint attention, children with autism show a reduced tendency to use eye contact and deictic gestures (e.g., pointing or showing) to coordinate attention and share experiences with social partners visà-vis objects or events in the world (McArthur \& Adamson, 1996; Mundy, Sigman, Ungerer, $\&$ Sherman, 1986), even though they are able to disengage and shift attention (Leekam, López, \& Moore, 2000), follow a head turn (Leekam, Hunnisett, \& Moore, 1998), and detect what is at the focus of someone's gaze (Leekam, Baron-Cohen, Perrett, Milders, \& Brown, 1997). There is evidence that they are less likely to share affect in episodes of joint attention (Kasari et al., 1990), they are more distinctive in their failure to point to and show rather than request things (Landry \& Loveland, 1988; Mundy et al., 1986), and they are limited in their responsiveness to others in settings that would typically elicit social referencing (Charman et al., 1997; Sigman et al., 1992). These areas of impairment appear to involve not merely lack of attentiveness or even affective responsiveness to other people (Sigman \& Capps, 1997), but also a lack of sharing of the kind that entails a partial movement into or assimilation of the stance, the attitude, or the communicative intention of the other (Hobson, 1993, 2002/2004).

We stress two points that arise out of this body of research. First, from a developmental perspective, young children with autism have been observed and/or reported to show reduced one-to-one intersubjective engagement and responsiveness from early in life, as well as impairments in joint attention and other forms of "secondary intersubjectivity" (Charman et al., 1997; Wimpory et al., 2000). Indeed, such impairments in person-to-person engagement are also evident in adolescents with autism (Hobson \& Lee, 1998). Therefore, it is highly plausible, if yet to be established, that aspects of joint attention presuppose qualities of interpersonal engagement, both across development and in moment-to-moment social exchanges. Second, the evidence suggests that within the domain of joint attention, there is a dissociation not only between initiating and RJA, but also between forms of joint attention that involve sharing experiences and feelings (relatively absent in many children with autism), and those that reflect more instrumental forms of social transaction (Kasari et al., 1990; Mundy, 1995). Therefore, there are grounds for exploring whether there is a common social-developmental process implicated both in establishing emotionally configured one-to-one intersubjective engagement, and in "sharing" forms of joint attention, and perhaps also implicated in other forms of social coordination such as imitation.

In this latter respect, there is substantial evidence that children with autism have characteristic limitations in imitating other people, for example, when copying meaningless, non-goal-directed actions and facial expressions (DeMyer et al., 1972; Rogers, Hepburn, Stackhouse, \& Wehner, 2003). Yet, they are able to copy others' goal-directed actions on objects and gestures when they are motivated 
or encouraged to do so (e.g., Beadle-Brown \& Whiten, 2004; Charman \& Baron-Cohen, 1994; Hobson \& Lee, 1999; Morgan, Cutrer, Coplin, \& Rodrigue, 1989; Stone, Ousley, \& Littleford, 1997), even though they may have a reduced tendency to imitate even simple objectrelated actions (Charman et al., 1997; Rogers et al., 2003). They also have difficulties in pantomiming actions in the absence of an object, or in using an object for novel purposes (Bartak, Rutter, \& Cox, 1975; Curcio \& Piserchia, 1978; Hammes \& Langdell, 1981; Heimann, Ullstadius, Dahlgren, \& Gillberg, 1992; Rogers, Bennetto, McEvoy, \& Pennington, 1996). Moreover, just as these children's delayed echolalia and personal pronoun reversals are unusual for their anchorage of the communicative act in an original situation as experienced by the child, but not shared with (or experienced through) other people (e.g., Charney, 1981; Hobson, 1990; Kanner, 1943), several studies have reported an incidental observation that children show imitative "reversal errors," for example, when they copy a model who displays her hands facing outward, by facing their own hands inward (Ohta, 1987; Smith \& Bryson, 1998; Whiten \& Brown, 1998).

Such failures in imitating self-/other orientation in actions have been the focus of three published studies. In the first of these (Hobson \& Lee, 1999), individuals with autism were unusual not only in failing to copy the self-/other orientation of actions, for example, omitting to place an object against their shoulder when the demonstrator had placed it against his, but also in adopting the harsh or gentle style with which actions had been demonstrated. The authors speculated that whereas the children without autism identified with and copied the person of the demonstrator, those with autism copied the demonstrator's goal-directed actions. The second study (Meyer \& Hobson, 2004) created the basis for the present investigation. We tested matched children with and without autism for their propensity to imitate self-other orientation in four different actions on objects. Although all of the children copied the actions, those with autism were significantly less likely to imitate the self-/other orientation of the actions. Although half of the children in the comparison group copied the self-/other orientation of the actions on at least half of the eight trials, for example, only 3 out of the 16 children with autism did so; and from a complementary perspective, 6 of the participants with autism imitated self-other orientation on fewer than two occasions, whereas only 1 participant in the comparison group did so as infrequently as this. Five of the children with autism, but none in the comparison group, showed a predominant pattern of replicating the actions as seen from their own perspective, akin to the "reversal errors" described above. The third study (Hobson \& Meyer, 2005) demonstrated that children with autism were less likely to show or imitate selfreferential behavior when communicating to someone else where on her body to place a sticker-badge.

Finally, what of the evidence for a positive relation between joint attention and imitation among individuals with autism? Again the evidence is relatively sparse. In a study of 24 children with autism of mean age 34 months, Rogers et al. (2003) reported that affected children's performance on tests of imitation (three manual acts, three actions on objects, and three oral-facial movements) were correlated with the frequency of IJA for the purpose of commenting, even when taking developmental level into account, and also correlated with social responsivity but not after variance associated with developmental level was considered. Carpenter, Pennington, and Rogers (2002) also reported a positive relation between the presence of "joint engagement" (referential looking, i.e., looking from an object to the adult's face and back to the same object) and imitative learning of goaldirected instrumental or arbitrary actions among children with autism, although they also noted that their measure of joint engagement (i.e., requiring only one triadic look during a session of $45 \mathrm{~min}$ ) was not a sensitive one (see also Ingersoll, Schreibman, \& Tran, 2003; Roeyers, Van Oost, \& Bothuyne, 1998). Such evidence is highly suggestive, but lacking in specificity concerning the links between different aspects of joint attention and imitation. 


\section{Hypothesis and Predictions}

The hypothesis that underpins the present study is that from early in life, there is a common factor implicated in the human abilities (a) to establish emotionally configured one-to-one intersubjective engagement, (b) to engage in "sharing" forms of joint attention, and (c) to achieve forms of imitation in which personal stances or roles are reversed. This common factor is a biologically grounded process, that of identifying with someone else. A second hypothesis is that children with autism have less of a propensity and/or ability to identify with another person, and that this is a source of abnormality in interpersonal relatedness, joint attention, and imitation.

Our hypothesis pivots on the notion of "identifying with" someone else. One helpful definition of identification is that provided by Laplanche and Pontalis (1973): "Psychological process whereby the subject assimilates an aspect, property, or attribute of the other and is transformed, wholly or partially, after the model the other provides." For the present purposes, it is appropriate to narrow the definition as it applies to the setting of an experimental task: to identify with someone else is to relate to the actions and attitudes of someone else from the other's perspective or stance, in such a way that a person assimilates the other's orientation toward the world, including toward the self, so that this orientation becomes a feature of the person's own psychological repertoire (Hobson, 1993, 2002/2004; Hobson \& Lee, 1999; Hobson \& Meyer, 2005). When, through identification, an individual shares experiences of the world with someone else in joint attention, he or she both resonates to the attitudes of the other from the others' bodily anchored stance and maintains enough of his or her own starting state to make the sharing "sharing" (and not mere adjustment). Moreover, when the propensity to identify with someone else motivates imitation, typically this prompts the individual to adopt the other person's stance in behaving and relating to the world, rather than copying the person's actions per se. For this reason the individual tends to copy the style and self-/other orien- tation of the other's actions, a process that promotes role reversals in action and attitude.

Although we made three predictions, the first two of these might have been anticipated on the basis of previous research and/or alternative theoretical perspectives (e.g., Swettenham et al., 1998; Mundy \& Neal, 2001), and it was the third that was more specifically derived from our hypothesis. The first prediction concerned the motivation and propensity to engage with other people: we predicted that relative to matched children without autism, children with autism would be rated as spending more time looking at the objects, and less time looking at the tester, in the course of a test of imitation. In the second, we predicted that children with autism would be less likely to engage in "sharing" looks, and this would be a specific deficit in relation to relatively spared "checking" or "orientating" looks. This prediction, although in keeping with previous findings, entailed a novel focus upon that quality of looks that human judges can recognize as reflecting intersubjective personal/affective contact. Our third and critical prediction concerned individual differences within as well as across groups, namely that participants who showed sharing looks would be those who imitated self-/other orientation. This prediction derived from our hypothesis that sharing looks (but not checking or orientating looks) entail the same quality of interpersonal engagement, namely, engagement that involves identification, that structures and motivates self-/ other-orientated imitation.

Here we emphasize that the present study cannot yield decisive evidence that our own hypothesis is either more or less valid than several other theoretical approaches in the literature. Yet having said this, the prediction about the relation between sharing looks and self-/other-orientated aspects of imitation was derived directly from the identification hypothesis, and it is not obvious that it would have been generated or indeed espoused by those of any other theoretical persuasion. In addition, because the hypothesis concerned the relation between sharing experiences (Hobson, 1989) and imitation of self-/other orientation, it was appropriate to seek for measures to assess behavioral expressions of sharing, and 
Table 1. Participant characteristics

\begin{tabular}{lllllllll}
\hline \hline & \multicolumn{3}{c}{ Chronological Age } & & \multicolumn{3}{c}{ Verbal Mental Age } \\
\cline { 2 - 3 } \multicolumn{1}{c}{ Participants } & $M$ & $S D$ & Range & & $M$ & $S D$ & Range \\
\hline With autism $(n=16)$ & $11 ; 5$ & $2 ; 5$ & $5 ; 11-14 ; 11$ & & $6 ; 0$ & $2 ; 8$ & $2 ; 7-13 ; 9$ \\
Without autism $(n=16)$ & $11 ; 1$ & $2 ; 0$ & $7 ; 11-14 ; 6$ & & $5 ; 8$ & $2 ; 10$ & $2 ; 5-10 ; 7$ \\
\hline \hline
\end{tabular}

Note: Ages are presented in years;months; VMA British Picture Vocabulary Scales age equivalents.

because sharing per se is something that can only be judged by a person, we sought to establish whether different kinds of look described in the literature as joint attention, alternating, or referential looks could be rated reliably according to this further criterion. We do not presuppose that such ratings are or are not reducible to some combination of behavioral ratings. If such ratings were to be interpreted as indices of "sharing," still there would need to be evidence that they corresponded with judgments of sharing per se (otherwise, there would be no justification for supposing the measures were of sharing). Although our approach seemed most appropriate for testing our predictions, we also conduct a preliminary exploration of this issue.

\section{Method}

\section{Participants}

We tested two groups of children $(n=16$ per group), one with and one without autism but with learning disabilities, mild to moderate mental retardation, and/or developmental delays, who were between the ages of 6 and 14 years. Children were tested in their schools, and selected on the basis of parental consent to participate. All participants with autism displayed the patterns of impairment in social interaction and communication, coupled with repetitive or stereotyped interests and activities, characteristic of the disorder. We confirmed the clinical diagnosis by completing a $D S M-I V$ criteria checklist (American Psychiatric Association, 1994) on the basis of systematic interviews with teachers, and by having a psychologist with over 10 years' experience of using the Childhood Autism Rating Scale (CARS; Schopler, Reichler, \& Renner, 1988) rate classroom observations of the children according to this measure. The CARS covers such domains as social relatedness, verbal and nonverbal communication, repetitive behaviour, sensory abnormalities, emotion regulation, and cognitive abilities. On the CARS, where a score of 30 or above is taken to indicate autism, the ratings of the children with autism were $M=38.2, S D=6.4$, range $=31.5$ to 54.5 .

The children with and without autism were group-matched for chronological age and language performance on the British Picture Vocabulary Scales (BPVS; Dunn, Dunn, \& Whetton, 1982), the British version of the Peabody Picture Vocabulary Scale. The BPVS is a standardized, widely used measure of receptive vocabulary, assessing a cognitive ability that is relatively more impaired in persons with autism (Jarrold, Boucher, \& Russell, 1977; Lockyer \& Rutter, 1970). Participant characteristics appear in Table 1.

Verbal intelligence (from the BPVS) was very similar in the two groups: for children with autism, $M=54.2, S D=21.2$, range $=$ 28-107; and for the learning-disabled (LD) comparison group, $M=53.5, S D=23.0$, range $=23-100$. To assess participants' finemotor abilities and visual-motor integration skill, children were tested with the Beery Developmental Test of Visual-Motor Integration (VMI; Beery, 1997). The VMI presents a sequence of geometric forms that the child is asked to copy with paper and a pencil. This measure provides a standardized assessment of the ability to integrate visual and sensory information with motor (finger and hand move- 


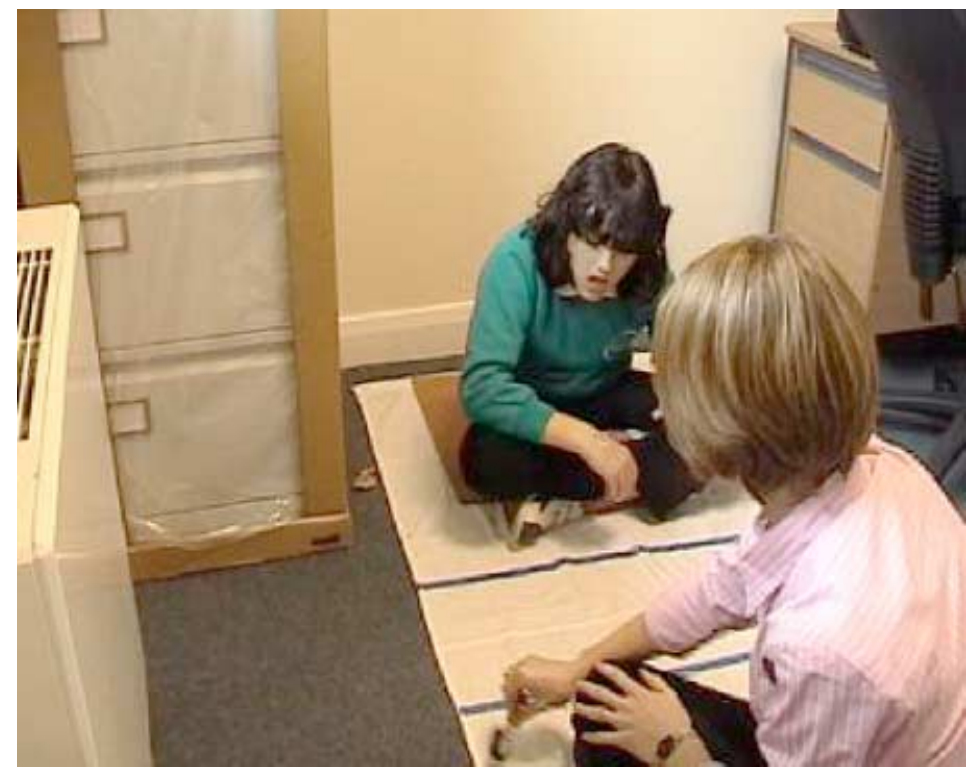

Figure 1. Testing arrangements and camera angle (tester demonstration: rolling wheel near self). [A color version of this figure can be viewed online at www.journals.cambridge.org]

ment) output. Children with autism $(M=$ 77.31, $S D=18.61$, range $=57-125)$ performed as well as the developmentally delayed control group $(M=65.56, S D=13.62$, range $=45-91)$.

\section{Previously reported procedure for testing self-/other orientation}

All of the children were well acquainted with the tester, and she met with them individually in quiet testing rooms in their own schools. The tester and child were seated directly across from each other on a testing mat at a distance of approximately 20 inches. There were four actions, each of which involved a different set of materials. Each of the four actions was presented in two different ways. For example, the experimenter picked up a small wheel with a metal handle (a castor from furniture) that had been placed in the middle of the testing mat, and proceeded to roll it from one side of the mat to the other, either across the mat directly in front of herself, as illustrated in Figure 1 (i.e., from left to right, neither away from nor toward herself) or, leaning forward, across the mat immediately in front of the participant. The remaining three conditions involved strumming a wooden stick along the serrated back of a wooden frog, stacking boxes, and tapping beanbags (in each case, either toward or away from the tester). For each of the four conditions, children saw the investigator produce the action in one of two possible orientations (close to or toward herself, or close to or toward the child) on the first testing session, and saw the alternative orientation for each condition in a second session on another day. After demonstrating each action, the tester returned the object(s) to their original positions and instructed the child: "Now you." There was no explicit instruction to copy what she had done. Details of our scoring procedure are provided in the original publication (Meyer \& Hobson, 2004). In brief, imitation of self-/other orientation was defined as the child adopting the examiner's demonstrated self-/other-anchored orientation, and therefore reversing the positioning of the object and directedness of the action. The children's scores (on which there was a significant group difference) are incorporated in the present study. Geometric repetition, a subclassification of nonself-/other-orientated imitative responses, was scored when the child's imitative response involved a reenactment of the dem- 
onstration (i.e., mimicking the original positioning of the objects in relation to his or her own body). There were only five children in the study, each of whom had autism, who used this as a primary response strategy, and these individuals are also reconsidered in relation to the present findings.

\section{Current study: Joint attention and imitation}

Coding and reliability. Figure 1 portrays the camera view and testing arrangements from our self-/other orientation study. The tester and child were seated directly across from one other on a testing mat. The camera angle always captured the child's entire face, the object, and the back of the tester's head and face so that the child's actions, gaze patterns, and facial expressions in relation to the tester could be coded. In Figure 1, for example, the tester is demonstrating rolling a wheel in relation to self, and the child is looking at the object. At the time of the original study, the tester was unaware that the videotapes would be coded for joint attention.

Videotapes were rated in a standardized fashion. To structure the rating episodes, these comprised both the model period, which commenced when the tester stated "watch this" and proceeded to demonstrate the action, and the response period, defined as commencing when the tester stated "now you" as she handed the materials to the child. The rating episode ended when the tester provided feedback (e.g., "well done") to the child regarding his or her performance and proceeded to remove the toy to begin the next task. This structure was imposed to ensure that only discrete, standard intervals of triadic engagement around each particular toy were rated. As a preliminary step, we determined that self-/other orientation (either toward or away from the self, or without orientation) could be rated reliably by independent judges, in that there was agreement on 23 out of 24 actions (and in the remaining case a child had rolled the wheel directly along the line that served to distinguish two of the categories).

As a first step, an independent naive judge coded the children's direction of gaze on a second by second basis using these rating epi- sodes. Gaze was rated as being directed either toward the tester's eyes/face, toward the object, or away. On the basis of eight participants ( $n=4$ per group), the primary naive judge and a second independent rater demonstrated excellent interrater reliability in recording the numbers of seconds spent directing gaze to the tester (intraclass correlation [ICC] = $.75)$, to the object $(\mathrm{ICC}=.94)$, or away $(\mathrm{ICC}=$ $.95)$.

The next stage involved the same primary naive judge revisiting each look to the tester, and providing a second rating with respect to the quality and/or function of the look according to the following mutually exclusive and exhaustive scheme. "Orientating looks" were those that appeared to occur in direct response to an action, sound, or movement on the part of the tester. "Sharing looks" were defined as those looks directed to the tester that could be seen to express a participant sharing experience through interpersonal contact with the tester. They involved a deep gaze that conveyed personal involvement (what Kanner, 1943, probably meant by the phrase "affective contact"), in contrast to checking looks that involved glances "at" the tester. "Checking looks" were defined as those looks toward the tester that were used to assess or check out either the situation or the tester's response. More detailed distinguishing characteristics between sharing and checking looks are presented in Table 2. We had established through pilot testing that although this approach to rating was subjective, in most instances the ratings of intersubjective qualities of engagement could be accomplished with confidence.

The second judge also revisited each of the joint attention looks $(n=27)$ for six randomly selected participants ( $n=3$ per group) and (blind to the first judge's ratings and all other aspects of the study) rated each as being either sharing, checking, or orientating in quality. The two independent judges agreed on 24 $(89 \%)$ of the 27 looks $(\kappa=.83$, excellent agreement according to Landis \& Koch, 1977). There were 6 looks that both judges agreed were "orientating," 8 looks that both agreed were "checking," and 10 looks which both agreed were "sharing." The three remaining looks were all judged to be "sharing" looks by 
Table 2. Distinguishing features of sharing and checking looks

\begin{tabular}{|c|c|c|c|}
\hline & \multicolumn{3}{|c|}{ Features of Looks } \\
\hline & Reciprocity & Depth & Contact \\
\hline Sharing & $\begin{array}{l}\text { Reciprocal: The participant } \\
\text { appears to register that the tester } \\
\text { is also looking to the participant. }\end{array}$ & $\begin{array}{l}\text { Deep: The look is } \\
\text { into the eyes of } \\
\text { the tester. }\end{array}$ & $\begin{array}{l}\text { Personal: The look manifests } \\
\text { affective contact with the } \\
\text { tester. }\end{array}$ \\
\hline Checking & $\begin{array}{l}\text { Nonreciprocal: The participant } \\
\text { appears to look to the tester } \\
\text { without registering the tester's } \\
\text { look to the participant. }\end{array}$ & $\begin{array}{l}\text { Superficial: The look } \\
\text { is at the eyes of } \\
\text { the tester. }\end{array}$ & $\begin{array}{l}\text { Impersonal: The look appears } \\
\text { to have the goal of monitor- } \\
\text { ing the tester's actions. }\end{array}$ \\
\hline
\end{tabular}

one rater and "checking" looks by the other. An alternative approach is to consider estimates of reliability of sharing versus all other kinds of look $(\kappa=.78)$, checking versus other kinds of look $(\kappa=.76)$, and orientating versus other kinds of look $(\kappa=1.0)$. These levels of agreement may appear unusually high, but mostly it was straightforward to "feel" (and judge) whether the looks seen on videotape were sharing, expressive of interpersonal engagement; checking, indicative of glancing up to check the tester's face for a reaction or instruction; or orientating where the tester made a clear movement or sound that attracted the child's attention.

We explored a further approach to rating the looks. In our view, the definitions we were using were specific and appropriate to what we were studying and also effective (operationally) insofar as they yielded satisfactory interrater reliabilities in the judgments of qualities of looking. However, we felt it would augment the study if we provided further description of complementary behavioral indices corresponding to the different categories of alternating looks. Therefore, we returned to our original ratings, and determined the duration of every look, where, perhaps, sharing looks might be expected to be longer than other kinds of look. It turned out that for both groups of participants, over $90 \%$ of each kind of look lasted for $1 \mathrm{~s}$ or less, and those looks that lasted between 2 and $3 \mathrm{~s}$ were distributed across the categories of look. The one look lasting $4 \mathrm{~s}$ was a sharing look by a child with autism. Second, we asked a new rater who was unaware of the nature of the study and the classes of look, to watch each look and record whether it was accompanied by a smile, where again, it might have been supposed that smiling would characterize sharing looks. Among children with autism, 8 (67\%) of the 12 sharing looks were accompanied by smiles, as were $10(29 \%)$ of the 35 checking looks and $3(21 \%)$ of the 14 orientating looks. Among children in the comparison group, $18(51 \%)$ of the 35 sharing looks were accompanied by smiles, as were $32(42 \%)$ of the 77 checking looks and $15(31 \%)$ out of the 49 orientating looks. These results indicate that many sharing looks were neither long nor accompanied by smiles and that frequently smiles accompanied other kinds of look.

Summary scores. The total testing (and therefore rating) time was about $1.5 \mathrm{~min}$ in length, but there were minor differences in total duration between the groups (for the children with autism: $M=80 \mathrm{~s}, S D=6 \mathrm{~s}$, range $=71-94 \mathrm{~s}$; and for the children in the comparison group: $M=95 \mathrm{~s}, S D=19 \mathrm{~s}$, range $=52-124 \mathrm{~s}$ ). In addition, although the entire duration of the rating episodes $(100 \%)$ were easily coded for most of the children (11 of the 16 children in the comparison group and 14 of the 16 children with autism), for the remaining 7 children, there were brief moments when the child's face was out of view of the camera or the tester's head blocked view of the child's gaze. For these reasons, results were considered on the basis of percentage of total rateable time (for directedness, a durational code) and rate of looks per rateable minute (for sharing, checking, and orientating looks, a fre- 
Table 3. Distribution of participants' gaze

\begin{tabular}{|c|c|c|c|c|c|c|c|c|c|}
\hline & \multicolumn{9}{|c|}{ Percentage of Time Looking } \\
\hline & \multicolumn{3}{|c|}{ Toward Tester } & \multicolumn{3}{|c|}{ Toward Object } & \multicolumn{3}{|c|}{ Away } \\
\hline & $M$ & $S D$ & Range & $M$ & $S D$ & Range & $M$ & $S D$ & Range \\
\hline With autism $(n=16)$ & 5.32 & 5.01 & $0-15$ & 93.41 & 5.28 & $85-98$ & 1.34 & 2.27 & $0-8$ \\
\hline Without autism $(n=16)$ & 12.05 & 7.70 & $1-24$ & 87.14 & 8.57 & $68-99$ & 0.81 & 1.92 & $0-7$ \\
\hline
\end{tabular}

quency code). The six variables of interest were thus percentage of time spent looking at the tester, the object, or away and the rate of looks per minute to the tester that were "sharing," "checking," or "orientating" in quality.

\section{Results}

For our principal a priori predictions, the data are analyzed using one-tailed tests.

\section{Directedness of gaze}

The descriptive data for directedness of gaze appear in Table 3 . The first point to note is how closely similar the groups were in how rarely they looked away from the tester and materials, on average about $1 \%$ of the time. Next, it may be observed that although both groups of children spent most of their time looking at the objects, the children with autism did so for a higher percentage (over 90\%) of the period, $t(30)=2.49, p<.05$, two tailed, with a medium effect size $(d=.7$; Cohen, 1992). Finally, there is a striking group difference in the deployment of gaze toward the tester: The children with autism looked at the tester for less than half as much time as children in the comparison group $(M \mathrm{~s}=5$ and $12 \%$, respectively), $t(30)=-2.92, p<.01$, one tailed, again with a large effect size $(d=$ $.82)$.

\section{Quality of joint attention looks}

Next we consider the number of each kind of joint attention look (sharing, checking, and orientating) to the tester. Table 4 conveys how, as a group, children with autism showed fewer of each kind of look. As we predicted, there was a group difference for sharing looks $t(30)=-1.78, p<.05$, one tailed, $d=.43$. When we consider checking looks, $t(30)=$ $-2.19, p<.05$, two tailed, $d=.57$, and orientating looks, $t(30)=-3.37, p<.05$, two tailed, $d=.88$, a similar pattern is evident. Indeed, at this level of analysis, the largest effect size (and difference between the groups) appears to be with respect to orientating looks, followed by checking looks, and then sharing looks.

However, when we consider quality of joint attention by individual participants, a different pattern emerges. As can be seen in Figure 2, 11 of the 16 children with autism compared with only 5 of the comparison children failed to engage in a single sharing look (Fisher exact $p=.038$, one tailed). This was not the case for other kinds of look. All but four of the children with autism (and one of the comparison children) showed at least one checking look and all but 5 of the children with autism and 2 of the comparison children showed at least one orientating look. Nonparametric repeated-measures comparisons confirmed that among participants with autism, the numbers of children engaging in at least one sharing, checking, and orientating look were not the same (Cochran $\mathrm{Q}=7.82, p=$ .02). Follow-up Wilcoxon Sign Tests revealed that, within the group of children with autism, fewer participants engaged in sharing than checking looks $(z=-2.65, p<.01)$ and in sharing than orientating looks $(z=-2.12$, $p<.05)$ whereas checking looks and orientating looks occurred for similar numbers of children $(z=-.38, p=.71)$. For the children in the comparison group, by contrast, the distri- 
Table 4. Frequency of sharing, checking, and orientating looks

\begin{tabular}{|c|c|c|c|c|c|c|c|c|c|}
\hline & \multicolumn{9}{|c|}{ Rate Per Minute for Each Type of Look } \\
\hline & \multicolumn{3}{|c|}{ Sharing } & \multicolumn{3}{|c|}{ Checking } & \multicolumn{3}{|c|}{ Orientating } \\
\hline & $M$ & $S D$ & Range & $M$ & $S D$ & Range & $M$ & $S D$ & Range \\
\hline With autism $(n=16)$ & 0.57 & 1.11 & $0-3.85$ & 1.60 & 1.97 & $0-6.43$ & 0.65 & 0.53 & $0-1.54$ \\
\hline Without autism $(n=16)$ & 1.45 & 1.64 & $0-5.05$ & 3.18 & 2.12 & $0-6.98$ & 1.94 & 1.44 & $0-4.33$ \\
\hline
\end{tabular}

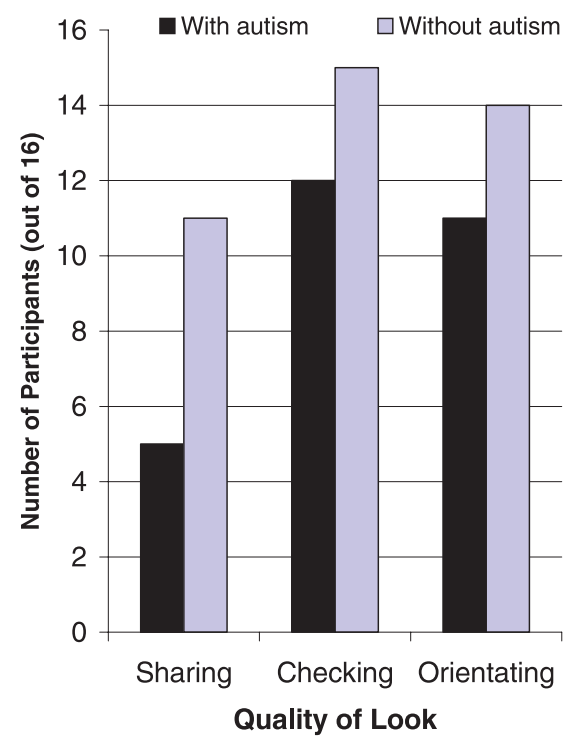

Figure 2. The number of children showing at least one sharing, checking, and orientating look. [A color version of this figure can be viewed online at www.journals.cambridge.org]

butions were not significantly different for numbers of children showing each kind of look at least once (Cochran $\mathrm{Q}=4.33, p=.12, n s)$.

Therefore, although we had not made a specific prediction about whether a limited tendency to engage in sharing looks would be because of group differences in frequency of looks or number of individual children who failed to show any such looks, the two measures yield complementary indices of the children's propensity for intersubjective engagement. Whereas children with autism engaged in less joint attention overall, relative to children in the comparison group, there were also a high number of children with autism who failed to engage in sharing looks at all, a finding specific both to type of look and to diagnostic group.

\section{Sharing looks and imitation of self-/other orientation}

Our third prediction concerned the relationship between a specific quality of joint attention, involving sharing looks, and a specific aspect of imitation, the propensity to imitate the self-/other-orientated aspects of the tester's actions. The children's performance on self-/ other orientation was evaluated in our previous investigation (Meyer \& Hobson, 2004) and we present histograms of those results and map on data from the present study in Figures 3 and 4. As we had predicted, children who had a propensity to engage in sharing looks were more likely to imitate self-/other orientation across the entire sample, Spearman $\rho(32)=.54, p<.001$, one tailed. As illustrated in Figures 3 and 4, this was the case separately for the children with autism, Spearman $\rho(16)=.49, p<.05$, one tailed, and for those in the comparison group, Spearman $\rho$ $(16)=.47, p<.05$, one tailed. By contrast, the rate per minute of other kinds of looking was not related to the children's scores on imitation of self-other orientation: for checking looks, Spearman $\rho(32)=.28$, and for orientating looks, Spearman $\rho(32)=.01$. Therefore, the positive result was specific to those looks which involved sharing.

Across the entire sample, there was a significant correlation between rates of checking and rates of sharing looks, Spearman $\rho(32)=$ .62. Given this, there was a significant difference between the correlations for rates of shar- 


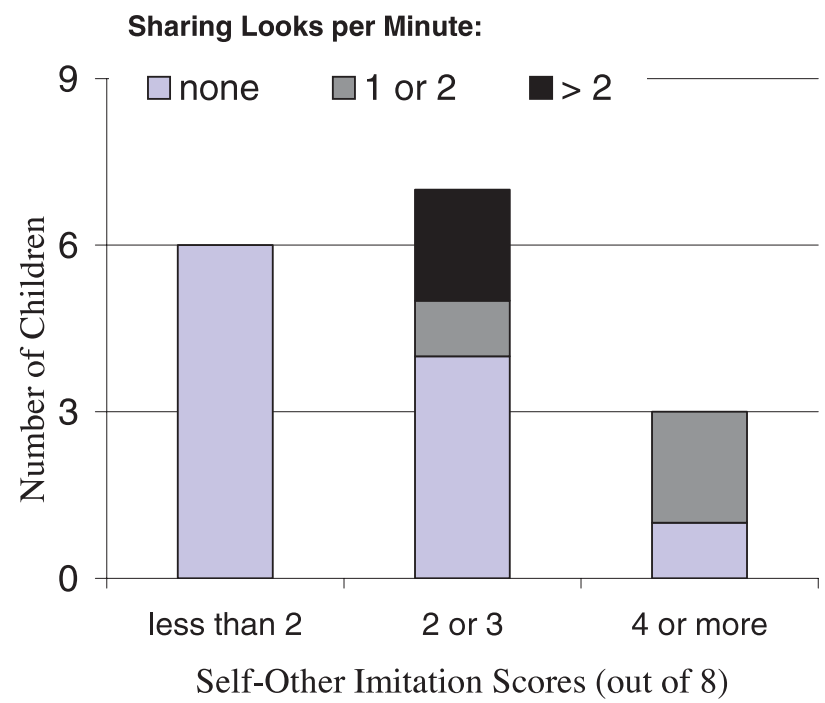

Figure 3. Participants with autism $(n=16)$ : sharing looks superimposed on self-/other imitation scores. [A color version of this figure can be viewed online at www.journals.cambridge.org]

Sharing Looks per Minute:

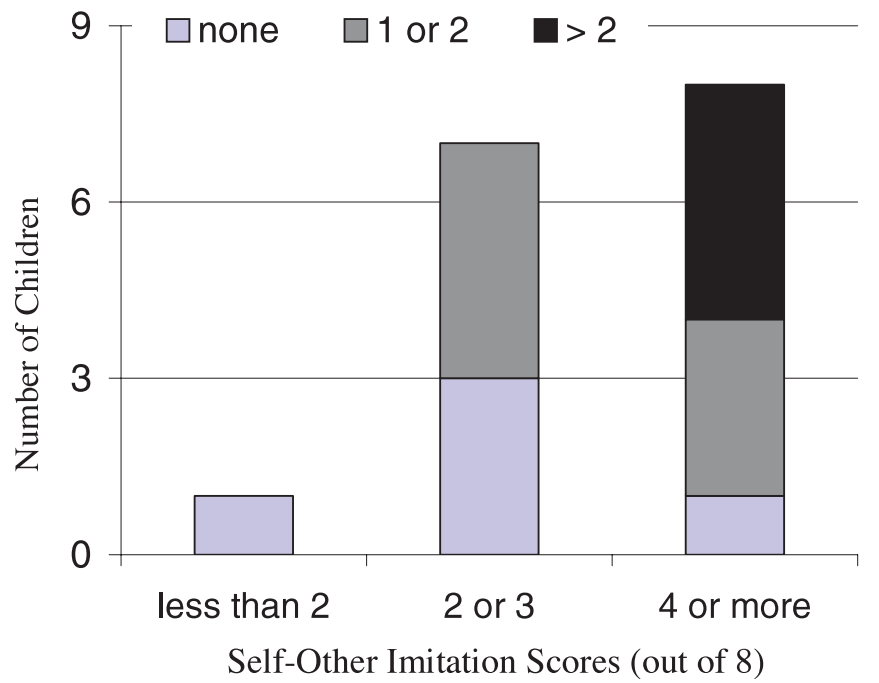

Figure 4. Participants in the comparison group $(n=16)$ : sharing looks superimposed on self-/other imitation scores. [A color version of this figure can be viewed online at www.journals.cambridge.org]

ing and for rates of checking looks with imitation of self-other orientation $(t=1.91$, $p<.05$, one tailed). However, this difference of .26 between the correlations should be interpreted with caution given the small sample size and hence low reliability for a difference of this magnitude $(90 \%$ confidence interval $=$ .03-.49).
From Figure 3, it can be seen in the darker portions of the bars how all five children with autism who ever engaged in sharing looks, also imitated self-other orientation at least twice. From a complementary perspective, all six of the children with autism who imitated self-other orientation on fewer than two occasions also failed to engage in any sharing 
looks. In contrast, there were five children in this group who showed some adjustment to self-other orientation without sharing looks, which raises the question of whether there might be other routes to this form of response (e.g., understanding the action as toward or away from an agent's body, or identifying with someone without this being reflected in looking).

Both self-other imitation and sharing looks were more frequent in the comparison children, yet Figure 4 illustrates how a similar pattern of the relation between self-other imitation and sharing looks is present. Of the seven comparison children who imitated selfother orientation on four or more occasions, six of these engaged in sharing looks, and four of these children did so at a rate of over two per minute. The one child in the comparison group who imitated self-/other orientation on fewer than two occasions failed to engage in any sharing looks.

\section{Developmental considerations}

Chronological age and profiles of looking. Across the sample of children, as well as within each group, those who were younger tended to look toward the tester more. Overall, there was an inverse relationship between chronological age and joint attention for sharing looks, Spearman $\rho(32)=-.51, p<.01$, checking looks, Spearman $\rho(32)=-.36, p<.05$, and orientating looks, Spearman $\rho(32)=-.46$, $p<.01$. In this regard, the tester had noted how some of the older children and adolescents tended to show more (perhaps normative) social inhibition, and look to her less during interactions.

However, the pattern appeared to be different in each group. For children with autism, only sharing looks decreased significantly with age, Spearman $\rho(16)=-.61, p<.05$ (checking $\rho=-.25$, orientating $\rho=-.08)$. The inverse correlation between chronological age and sharing looks was significantly stronger than that between chronological age and checking looks or orienting looks $(t=1.77$ and $1.80, p<.05$, one tailed, respectively). By way of illustration, four out of the five children with autism who ever showed a sharing look were under 10 years, and only one of the 10 children over this age ever showed such a look.

The picture was different for the children without autism. Within this group, only checking and orientating looks decreased significantly with age, Spearman $\rho(16)=-.50$, $p<.05$, and $\rho(16)=-.78, p<.001$, respectively (sharing $\rho=-.38$ ). Here, the inverse correlation between chronological age and sharing looks was significantly weaker than that for orientating looks $(t=1.96, p<.05)$, but not for checking looks. Despite this, the inverse correlation between chronological age and sharing looks was not significantly different between the groups $(z=-.78, n s)$.

Overall, therefore, there was suggestive evidence that the inverse relation between age and sharing looks vis-à-vis other kinds of look was specific to the participants with autism.

\section{Chronological age and self-/other-orientated} imitation. Across the sample, chronological age was not correlated with self-/otherorientated imitation, $\rho(32)=.02$. Once again, however, the associations between chronological age and self-/other-orientated imitation were different within the participants of each group. In the case of children without autism, it appeared that the older children were nonsignificantly more likely to adopt self-/otherorientated imitation $(\rho=.45)$, whereas the nonsignificant association was in the opposite direction for participants with autism ( $\rho=$ $-.25)$, and the difference between these correlations was significant $(z=1.89, p<.05)$.

These results present something of a paradox. Why should children with autism not be showing the expected age-related improvements on the imitation task? Perhaps sharing looks hold the key.

Chronological age and sharing looks revisited. When we considered the variance associated with chronological age, the relation between sharing looks and imitation of self-/other orientation remained both across the groups, and for the children with autism: partial $r(32)=$ .64 , partial $r(16)=.44$ (Cohen \& Cohen, 1983). It is more striking that, when the variance associated with sharing looks was con- 
sidered for the children with autism, the relation between chronological age and imitation of self-/other orientation changed from $\rho=-.25$ to partial $r=.07$. This result provides supplementary evidence that the association between sharing looks and self-/other-orientated imitation is critical for children with autism.

Developmental abilities. Only one out of six correlations between each kind of look and verbal MA and verbal IQ was significant when considered in isolation (and therefore this was of uncertain status): verbal MA was negatively correlated with orientating looks at a level of -.43 . In addition, VMI ability was not significantly associated with sharing looks, either within or across the groups.

\section{Further observations}

The group of 5 (out of the 16) children with autism who engaged in sharing looks spent a relatively high proportion of time looking at the tester $(M=11 \%, S D=4.99)$, although there were individual differences in this regard $($ range $=3.4-15.4 \%$ ). They showed a broad range of cognitive ability (IQ range $=$ 43-107) and chronological age (range $=5$ years, 11 months to 12 years, 11 months). From a complementary perspective, the five children in the comparison group who did not engage in any sharing looks were all far below their group mean in the percent of time they spent looking at the tester (range $=1.2-$ $9.2 \%$ ), and were also in the lower range of cognitive ability (IQ range $=30-71$ ).

In our original study, there were five children with autism who were unusual in that they used "geometric repetition" as their primary response mode of imitating. For the majority of their imitative responses, these children copied the orientation of the object as they had observed it relative to themselves, exactly as had happened in the demonstration. This group of children were relatively low in the time they spent looking at the tester (between 2 and $7 \%$ of the time) vis-à-vis the object (range $=92-98 \%$ ). Only one of the five children ever engaged in a sharing look, although all five showed checking looks and three showed orientating looks. Of the three children with autism who imitated self-/other orientation as a principal response mode, two were unusual in looking at the tester 13 and $14 \%$ of the time, which was above the mean of the children in the comparison group. The third child was also unusual in that he never looked in the tester's eyes during the imitation tasks, and during classroom interactions, appeared to avoid eye contact as if he might find it overwhelming.

\section{Discussion}

In the introduction to this paper, we drew attention to evidence that renders it plausible that the process of identification is operative in certain forms of interpersonal engagement, joint attention, and imitation that characterize typically developing infants, and that this process is specifically impaired in children with autism. Our reasoning was that if, as had already been demonstrated, individuals with autism were less prone to copy the self-/other orientation of someone else's actions, then this probably reflected failures in identification that would also be manifest in other indices of interpersonal engagement.

Our first prediction was inspired by the work of Carpenter et al. (1995), who demonstrated a relation between joint attention and imitation in typically developing children and chimpanzees. Like these authors, we considered that an individual who copies a person's way of behaving is more likely to have engaged with that person in joint attention, whereas one who does not might be preoccupied with the object acted upon. Therefore, we predicted that when compared with control participants on our imitation task, those with autism would spend relatively more time focused upon the object than the demonstrator. As in the Carpenter et al. (1995) study, and in keeping with other evidence in the literature (Kasari et al., 1990), participants in both groups spent the majority of time looking at the objects. However, these results also provided further evidence consistent with other literature (Swettenham et al., 1998) that children with autism spend relatively less time looking at people. 
Our second prediction was more specific. Here we were concerned to evaluate the quality of the joint attention shown by participants. Bearing much in common with the work of Adamson and Bakeman (1985), Bruner (1981), Hornick and Gunnar (1988), Kasari et al. (1990), and Mundy et al. (1992), we also considered that much of joint attention may express sharing of affective experience. We wanted to explore whether one can make meaningful distinctions among different forms of joint attention, which may involve varying degrees of sharing of experience and (according to our hypothesis) identification with another person. There was high reliability in the ratings of sharing looks, and these looks proved to be less prevalent among participants with autism, but this was also the case for checking and orienting looks. Therefore, all forms of joint attention were less frequently observed among participants with autism. In contrast, two-thirds of participants with autism never showed a "sharing" look, whereas this was the case for one-third of the comparison group. Individual profiles of looking revealed how only among participants with autism were there significantly fewer individuals who showed any sharing look, than who showed any checking and/or orienting look. Of interest, all but one of the five children with autism who showed a sharing look were under 10 years old, suggesting that interpersonal engagement may have a complex developmental course. However, because sharing looks tended to be less frequent than other kinds of look for both groups of participants, and the children with autism tended to show fewer looks of all kinds, one should not overestimate the specificity of the dearth of sharing looks.

Our third and critical prediction was that sharing looks, and only sharing looks, would relate to imitation of self-/other orientation. The results indicated that, indeed, participants in each group who showed sharing looks tended to be those who imitated the demonstrator's self-/other orientation, whereas all those with the lowest scores of self-/other orientation also showed a complete absence of sharing looks. Here it should be recalled that our previous study had shown how as a group, children with autism were limited in their propensity to transpose a demonstrator's actions in relation to herself into actions in relation to themselves. Despite these differences in overall levels of performance, there remained sufficient within-group variance to establish that within each group, individual differences in sharing looks corresponded with individual differences in imitating self-/other orientation in actions. More detailed analyses of individual response patterns elaborated this picture, for instance in revealing that only one of the five children with autism who showed a predominance of geometric (i.e., exact) repetition in the imitation task ever engaged in a sharing look, and all tended to be object-focused in looking.

Several aspects of the results deserve special consideration. First, they were derived from groups of relatively modest size, and replication is needed. Sample sizes this small do not allow for a reliable estimate of the true level of association among variables because the confidence limits around correlations, and differences between correlations, are large. Second, all the children were "on task" nearly all the time, in that looks away from the object acted upon and/or the person of the demonstrator were few in number and brief in duration. Therefore, the group difference in overall looks to the tester was not simply the result of global inattentiveness among participants with autism; rather, it represented a different deployment of attention (perhaps more accurately, a different pattern of psychological engagement with person and object) by participants in the two groups. It is important to note that not only looks to share, but also looks to check and looks to orientate in relation to the demonstrator, were less frequent among participants with autism. Whatever motivates a participant to look to someone else in a testing situation such as this, therefore, and whatever the draw to giving some form of attention to the other person, something that extends beyond a wish to share experiences, this distinguishes individuals with and without autism. Perhaps it would be more accurate to state that the groups differed in the relative "pull" toward objects and people, in that it is possible that participants with autism became (relatively, albeit not markedly) fixed in look- 
ing at the objects. Therefore, at this level of description, one might consider the group difference to reflect a distinction in terms of social orientation (Dawson, Meltzoff, Osterling, Rinaldi, \& Brown, 1998; Mundy \& Neal, 2001).

Third, it is not clear whether the results reflect something enduring about individual differences among participants, something about the connection between their pattern of engagement in this particular setting and their imitative performance, or some mixture of the two. For instance, one can imagine that on a given day an individual of either group might feel less than usually inclined to become involved with the tester, and for this reason deploy his or her attention to the objects of the task and as a result fail to imitate self-/other orientation. Such a person might behave differently on another occasion, even though the relation between sharing looks and imitation might still hold. Although such a possibility does not undermine the observed group differences, it does serve to highlight how the experimental procedure provides a very brief snapshot of a particular set of goings on.

Fourth and finally, it is important to note that although the results indicated that specifically sharing looks (and not other kinds of look) were related to imitating self-/other orientation, we did not examine whether sharing looks were related to other aspects of imitation. Earlier we cited evidence that among children with autism, joint attention may be related to the children's ability to imitate other kinds of action. Therefore, it remains to establish how far the present results reflect a "special case" of the relation between a specific form of joint attention and a specific form of imitation, or how far this relation might apply more broadly. Indeed, it is possible (and we believe, likely) that the processes that normally promote sharing forms of joint attention and role-sensitive adjustments in imitative behavior also operate to motivate attentiveness to and imitation of other people in more general respects.

These considerations bear upon the choice of which among several approaches might be most appropriate in interpreting the results. For example, one might focus on domain- general abilities such as participants' attention regulation skills (e.g., Hughes \& Russell, 1993; Landry \& Bryson, 2004), and consider how those individuals who fail to sustain or distribute their attention in a typical way might show few sharing looks and at the same time, fail to notice or copy all aspects of demonstrated actions. From the perspective of socialcognitive mental representation (e.g., Frith, Morton, \& Leslie, 1991), in contrast, one might consider that individuals who fail to "decouple" their own and others' representations of the world would not only show limited joint attention vis-à-vis the world, but also a lack of sensitivity to (and imitation of) the kinds of person-anchored stance tested here. Even if one adopts a theoretical framework concerned with the structure of self-other relations, it might be possible to explain the present findings in terms of disturbances in the self-/other monitoring of actions (e.g., Russell \& Jarrold, 1999) rather than deficits in interpersonal engagement. Finally, given that participants' rates of smiling during the sharing looks in our study were similar to rates previously reported for rates of positive affect in joint attention (Kasari et al., 1990; Mundy et al., 1992), one might focus on the children's difficulties in expressing and sharing affect during joint attention. We do not know whether advocates for each of these positions would have predicted our findings, and so we acknowledge that the study cannot rule out explanations that either conflict with our own, or offer a complementary account on a different level of explanation.

Consider what is perhaps the most plausible alternative explanation for the present findings: the social-orienting model of autism proposed by Mundy and Neal (2001). These authors suggest that "an early cardinal deficit in social-orienting and joint attention contributes to a severe impoverishment of social information processing input during infancy and preschool development in children with autism" (pp. 139-140). This disturbance "may reflect an early onset error in sensitivity to the reward value of social interaction ... [but] the mechanism of attenuation in social reward sensitivity is poorly understood at this time" (pp. 151-152). Importantly, and like our own hypothesis, this account stresses the motiva- 
tional (and potentially, affective) as well as cognitively structuring aspects of propensities to engage with other persons. Whether or not identification is as foundational as we believe, and whether a limited propensity to identify with others explains the "attenuation in social reward sensitivity" among persons with autism, it remains important for alternative theories such as the social-orienting account to explain role-reversing aspects of communication and imitation and the interpersonally grounded movements in stance manifest among typically developing infants of around 1 year old, and relatively limited among those with autism. Arguably, the notion of identification is also apt for explaining why, if one applies appropriate measures to assess qualities of interpersonal relatedness, then one finds evidence of marked impairment in autism (e.g., García-Pérez, Lee, \& Hobson, in press; Hobson \& Lee, 1999).

Finally, there are philosophical and logical reasons why one might invoke a process like identification to explain how sharing of experiences (Hobson, 1989), or adjustment of perspective through responsiveness to the attitudes of others, or the emergence of reflective self-awareness (Cooley, 1902; Hobson, 1990; Mead, 1934), or even the acquisition of context-sensitive language and creative symbolic thinking (Adamson, 1995; Hobson, 2000; Werner \& Kaplan, 1963), emerge in the course of early development. Sharing experiences entails that to some degree, one participates in another person's psychological stance vis-àvis objects or events, so that one achieves a now expanded subjective state. As the philosopher Campbell (2002) describes, in sharing it is constitutive of your experience that the other is, with you, attending to something (and for related perspectives see Bråten, 1998; Decety \& Sommerville, 2003; Hobson, 1993, 2002/2004; Gallese \& Goldman, 1998; Meltzoff \& Brooks, 2001; Mundy, 2003; Tomasello, 1995).

There remains much to discover about the bases for, and development of, the process or processes of identification. The most in-depth treatment of identification has been within psychoanalytic writings, and it is clear that although Freud (1955/1921) considered iden- tification to be a basic feature of mental life that underlies empathy, he also wrote of more complex forms such as identification with one's father. It is not surprising that the notion of identification has links with other current account of self-other connectedness such as those inspired by neurofunctional evidence for mirror neurones (e.g., Decety \& Sommerville, 2003; Gallese, 2001) and theoretical treatments of early imitation, especially by Meltzoff (e.g., Meltzoff \& Moore, 1998a). There is also evidence from functional magnetic resonance imaging findings (Dapretto et al., 2006) and EEG patterns of mu frequency suppression (Oberman et al., 2005) that such functioning may be atypical among children with autism (Williams, Whiten, Suddendorf, \& Perrett, 2001). The points we stress are, first, that we are dealing with the propensity to be moved into the psychological stance of another person, even as one relates to that someone else from one's own position and, second, that this involves being moved in attitude and affective orientation, not merely copying actions. Insofar as this structure of self-other engagement (being drawn into and encompassing the orientation of the other so that this yields sharing of subjective mental states and at the same time a new potential orientation for oneself) is critical in shaping one's experience of social relations, identification provides the basis for a developmental series of increasingly elaborated representations of self-other relatedness.

Such an account has important implications for understanding typical development, as well as for characterizing the developmental psychopathology of autism. For example, differences in children's ability to incorporate the attitudes of others through identification may have significant implications for their achieving new perspectives or "takes" in relation to the world (through imitation, social referencing, joint attention, and so on), a new reflective stance in relation to themselves and their own mental contents (as in metarepresentation), and the development of social emotions such as guilt and concern (Hobson, Chidambi, Lee, \& Meyer, 2006). Correspondingly, if it is the case that children with autism are limited in the propensity to identify with others, then this may contribute to their 
relative lack of initiative in creating or responding to new conceptual perspectives, as well as to their restricted and abnormal linguistic and social-communicative repertoires and limitations in executive functioning (e.g., Dawson et al., 2002; García-Pérez et al., in press; Griffith, Pennington, Wehner, \& Rogers, 1999; Minshew, Meyer, \& Goldstein, 2002).

It remains to consider how one might conduct further tests of the hypothesis that children with autism have a limited propensity to identify with other people. There is a difficulty here: there may be sustained joint attention or alternating looks between the world and someone else that reflect only minimal or moderate amounts of sharing of experience, or instances when the copying of actions may not be the outcome of engagement with the person who acts (as discussed in Hobson \& Lee, 1999). From a complementary perspective, the pull to identify with someone else may account for a part of the propensity to imitate at all, even when the copying is of goal-directed actions (where identification need not structure the form of the imitation). Therefore, one challenge for future studies is to find new ways to examine whether there are indeed aspects of psychological functioning that are potentially dissociable according to whether or not they entail identification, and whether these bear meaningful relations to one another. For example, we have adopted this perspective in designing studies involving participants with autism on nonverbal communication (and specifically the coordination of head shaking and nodding between conversational partners: García-Pérez et al., in press),

\section{References}

Adamson, L., \& Bakeman, R. (1985). Affect and attention: Infants observed with mothers and peers. Child Development, 56, 582-593.

Adamson, L. B. (1995). Joint attention, affect, and culture. In C. Moore \& P. J. Dunham (Eds.), Joint attention: Its origins and role in development (pp. 205221). Hillsdale, NJ: Erlbaum.

American Psychiatric Association. (1994). Diagnostic and statistical manual of mental disorders (4th ed., rev.). Washington, DC: Author.

Bacon, A. L., Fein, D., Morris, R., Waterhouse, L., \& Allen, D. (1998). Responses of autistic children to the distress of others. Journal of Autism and Developmental Disorders, 28, 129-142. imitation (and specifically the imitation of "style": Hobson \& Lee, 1999; Hobson \& Meyer, 2007); and the use of personal pronouns (e.g., Lee, Hobson, \& Chiat, 1994). Each of these approaches affords the opportunity to evaluate the degree to which individuals either relate to "surface" features of behavior or communication, or perceive, adapt to, and adopt the person-anchored stance that such behavior or communication expresses. There is scope to extend such studies to changes in an individual's repertoire over time, for instance in relation to self-regulation or the ability to apply concepts flexibly.

We conclude by returning from the big picture to more local outcomes of this study. The present results represent new and challenging findings about the nature of joint attention deficits in individuals with autism. Not only are such individuals less likely to look to another person when copying that person's actions on objects, but they are also less prone to engage in sharing looks, and when this is the case, they are also less likely to imitate the self-/other-orientated aspects of the actions demonstrated. To explain this pattern of results, it may be necessary to take account of a broad set of social-relational phenomena characteristic of typical and atypical development, and to rethink what an individual brings to and takes from experiences of interpersonal engagement. Future research promises to reveal how far aspects of self-other relatedness that entail sharing and role flexibility are developmentally significant for the emergence and operation of higher cognitive functioning as well as for shaping social relations.

Bakeman, R., \& Adamson, L. (1984). Coordinating attention to people and objects in mother-infant and peerinfant interaction. Child Development, 55, 1278-1289.

Bartak, L., Rutter, M., \& Cox, A. (1975). A comparative study of infantile autism and specific developmental receptive language disorder: I. The children. British Journal of Psychiatry, 126, 127-145.

Beadle-Brown, J. D., \& Whiten, A. (2004). Elicited imitation in children and adults with autism: Is there a deficit? Journal of Intellectual and Developmental Disability, 29, 147-163.

Beery, K. E. (1997). The Beery-Buktenica Developmental Test of Visual-Motor Integration. Parsippany, NJ: Modern Curriculum Press. 
Bråten, S. (1998). Infant learning by altercentric participation: The reverse of egocentric observation in autism. In S. Bråten (Ed.), Intersubjective communication and emotion in early ontogeny (pp. 105-126). Cambridge: Cambridge University Press.

Bruner, J. (1981). Learning how to do things with words. In J. Bruner \& A. Garton (Eds.), Human growth and development. London: Oxford University Press.

Campbell, J. (2002). Reference and consciousness. Oxford: Oxford University Press.

Carpenter, M., Nagell, K., \& Tomasello, M. (1998). Social cognition, joint attention, and communicative competence from 9 to 15 months of age. Monographs of the Society for Research in Child Development, 63 , $1-143$.

Carpenter, M., Pennington, B. F., \& Rogers, S. J. (2002). Interrelations among social-cognitive skills in young children with autism. Journal of Autism and Developmental Disorders, 32, 91-106.

Carpenter, M., Tomasello, M., \& Savage-Rumbaugh, S. (1995). Joint attention and imitative learning in children, chimpanzees, and enculturated chimpanzees. Social Development, 4, 217-237.

Charman, T., \& Baron-Cohen, S. (1994). Another look at imitation in autism. Development and Psychopathology, 6, 403-413.

Charman, T., Baron-Cohen, S., Swettenham, J., Baird, G., Cox, A., \& Drew, A. (2000). Testing joint attention, imitation, and play as infancy precursors to language and theory of mind. Cognitive Development, 15, 481-498.

Charman, T., Swettenham, J., Baron-Cohen, S., Cox, A., Baird, G., \& Drew, A. (1997). Infants with autism: An investigation of empathy, pretend play, joint attention, and imitation. Developmental Psychology, 33, 781-789.

Charney, R. (1981). Pronoun reversal errors in autistic children: Support for a social explanation. British Journal of Disorders of Communication, 15, 39-43.

Cicchetti, D. (1993). Developmental psychopathology: Reactions, reflections, projections. Developmental Review, 13, 471-502.

Cohen, J. (1992). A power primer. Psychological Bulletin, $112,155-159$.

Cohen, J., \& Cohen, P. (1983). Applied multiple regression/ correlation analysis for the behavioural sciences (2nd ed.). Hillsdale, NJ: Erlbaum.

Cooley, C. H. (1902). Human nature and the social order. New York: Charles Scribner \& Sons.

Curcio, F., \& Piserchia, E. A. (1978). Pantomimic representation in psychotic children. Journal of Autism and Childhood Schizophrenia, 8, 181-189.

Dapretto, M., Davies, M. S., Pfeifer, J. H., Scott, A. A., Sigman, M., \& Bookheimer, S. Y., et al. (2006). Understanding emotions in others: Mirror neuron dysfunction in children with autism spectrum disorders. Nature Neuroscience, 9, 28-30.

Dawson, G., Hill, D., Spencer, A., Galpert, L., \& Watson, L. (1990). Affective exchanges between young autistic children and their mothers. Journal of Abnormal Child Psychology, 18, 335-345.

Dawson, G., Meltzoff, A. N., Osterling, J., Rinaldi, J., \& Brown, E. (1998). Children with autism fail to orient to naturally occurring social stimuli. Journal of Autism and Developmental Disorders, 28, 479-485.

Dawson, G., Munson, J., Estes, A., Osterling, J., McPartland, J., \& Toth, K. (2002). Neurocognitive function and joint attention ability in young children with au- tism spectrum disorder versus developmental delay. Child Development, 73, 345-358.

Dawson, G., Osterling, J., Meltzoff, A. N., \& Kuhl, P. (2000). Case study of the development of an infant with autism from birth to two years of age. Journal of Applied Developmental Psychology, 21, 299-313.

Decety, J., \& Sommerville, J. (2003). Shared representations between self and other: A social cognitive neuroscience view. Trends in Cognitive Sciences, 7, 527-533.

DeMyer, M. K., Alpern, D. G., Barton, S., DeMyer, W. E., Churchill, D. W., Hingtgen, J. N., et al. (1972). Imitation in autistic, early schizophrenic, and non-psychotic subnormal children. Journal of Autism and Childhood Schizophrenia, 2, 264-287.

DiLavore, P. C., Lord, C., \& Rutter, M. (1995). Prelinguistic autism diagnostic schedule. Journal of Autism and Developmental Disorders, 25, 355-379.

Dunn, L. M., Dunn, L., \& Whetton, C. (1982). British Picture Vocabulary Scale. Windsor: NFER-Nelson.

Field, T. M., Woodson, R., Greenberg, R., \& Cohen, D. (1982). Discrimination and imitation of facial expressions by neonates. Science, 218, 179-181.

Freud, S. (1955/1921). Identification. In J. Strachey (Ed.), The standard edition of the complete psychological works of Sigmund Freud (Vol. 18, pp. 105-110). London: Hogarth.

Frith, U., Morton, J., \& Leslie, A. M. (1991). The cognitive basis of a biological disorder: Autism. Trends in Neurosciences, 14, 433-438.

Gallese, V. (2001). The "shared manifold" hypothesis: From mirror neurons to empathy. Journal of Consciousness Studies, 8, 33-50.

Gallese, V., \& Goldman, A. (1998). Mirror neurons and the simulation theory of mind-reading. Trends in $\mathrm{Cog}$ nitive Science, 2, 493-501.

García-Pérez, R. M., Lee, A., \& Hobson, R. P. (in press). On intersubjective engagement: A controlled study of nonverbal communication in autism. Journal of Autism and Developmental Disorders.

Griffith, E. M., Pennington, B. F., Wehner, E. A., \& Rogers, S. J. (1999). Executive functions in young children with autism. Child Development, 70, 817-832.

Hammes, J., \& Langdell, T. (1981). Precursors of symbol formation and childhood autism. Journal of Autism and Developmental Disorders, 11, 331-346.

Heimann, M., Ullstadius, E., Dahlgren, S. O., \& Gillberg, C. (1992). Imitation in autism: A preliminary research note. Behavioural Neurology, 5, 219-227.

Hobson, R. P. (1989). On sharing experiences. Develop ment and Psychopathology, 1, 197-203.

Hobson, R. P. (1990). On the origins of self and the case of autism. Development and Psychopathology, 2, 163-181.

Hobson, R. P. (1993). Autism and the development of mind. Hove, Sussex: Erlbaum.

Hobson, R. P. (2000). The grounding of symbols: A socialdevelopmental account. In P. Mitchell \& K. J. Riggs (Eds.), Children's reasoning and the mind (pp. 1135). Hove: Psychology Press.

Hobson, R. P. (2002/2004). The cradle of thought. London/New York: Pan Macmillan/Oxford University Press.

Hobson, R. P. (2004). What puts the jointness in joint attention? In N. Eilan \& C. Hoerl (Eds.), Joint attention. Cambridge: Cambridge University Press.

Hobson, R. P., Chidambi, G., Lee, A., \& Meyer, J. A. (2006). Foundations for self-awareness: An exploration through autism. Monographs of the Society for Research in Child Development, 71 (Serial No. 284). 
Hobson, R. P., \& Lee, A. (1998). Hello and goodbye: A study of social engagement in autism. Journal of Autism and Developmental Disorders, 28, 117-126.

Hobson, R. P., \& Lee, A. (1999). Imitation and identification in autism. Journal of Child Psychology and Psychiatry, 40, 649-659.

Hobson, R. P., \& Meyer, J. A. (2005). Interpersonal foundations for the self: The case of autism. Developmental Science, 8, 481-491

Hobson, R. P., \& Meyer, J. A. (2007). Dissociable aspects of imitation and joint attention: A reappraisal through the study of autism. Unpublished manuscript.

Hobson, R. P., Patrick, M. P. H., Crandell, L. E., GarcíaPérez, R. M., \& Lee, A. (2004). Maternal sensitivity and infant triadic communication. Journal of Child Psychology and Psychiatry, 45, 470-480.

Hornick, R., \& Gunnar, M. (1988). A descriptive analysis of infant social referencing. Child Development, 59, 626-634.

Hughes, C., \& Russell, J. (1993). Autistic children's difficulty with mental disengagement from an object: Its implications for theories of autism. Developmental Psychology, 29, 498-510.

Ingersoll, B., Schreibman, L., \& Tran, Q. H. (2003). Effect of sensory feedback on immediate object imitation in children with autism. Journal of Autism and Developmental Disorders, 33, 673-683.

Jarrold, C., Boucher, J., \& Russell, J. (1977). Language profiles in children with autism: Theoretical and methodologcal implications. Autism: The International Journal of Research and Practice, 1, 57-76.

Kanner, L. (1943). Autistic disturbances of affective contact. Nervous Child, 2, 217-250.

Kasari, C., Sigman, M., Mundy, P., \& Yirmiya, N. (1990). Affect sharing in the context of joint attention interactions of normal, autistic, and mentally retarded children. Journal of Autism and Developmental Disorders, 20, 87-100.

Klinnert, M. (1984). The regulation of infant behavior by maternal facial expressions. Infant Behavior and Development, 7, 447-465.

Kugiamutsakis, G. (1998). Neonatal imitation in the intersubjective companion space. In S. Bråten (Ed.), Intersubjective communication and emotion in early ontogeny (pp. 63-88). Cambridge: Cambridge University Press.

Landis, J. R., \& Koch, G. G. (1977). The measurement of observer agreement for categorical data. Biometrics, 33, 159-174.

Landry, R., \& Bryson, S. E. (2004). Impaired disengagement of attention in young children with autism. Journal of Child Psychology and Psychiatry, 45, 1115-1122.

Landry, S. H., \& Loveland, K. A. (1988). Communication behaviors in autism and developmental language delay. Journal of Child Psychology and Psychiatry, 29, 621-634.

Laplanche, J., \& Pontalis, J. B. (1973). The language of psychoanalysis. London: Hogarth.

Lee, A., Hobson, R. P., \& Chiat, S. (1994). I, you, me and autism: An experimental study. Journal of Autism and Developmental Disorders, 24, 155-176.

Leekam, S., Baron-Cohen, S., Perrett, D., Milders, M., \& Brown, S. (1997). Eye-direction detection: A dissociation between geometric and joint attention skills in autism. British Journal of Developmental Psychology, 15, 77-95.

Leekam, S. R., Hunnisett, E., \& Moore, C. (1998). Tar- gets and cues: Gaze-following in children with autism. Journal of Child Psychology and Psychiatry, 39, 951-962.

Leekam, S. R., López, B., \& Moore, C. (2000). Attention and joint attention in preschool children with autism. Developmental Psychology, 36, 261-173.

Lockyer, L., \& Rutter, M. (1970). A five to fifteen year follow-up study of infantile psychosis: IV. Patterns of cognitive ability. British Journal of Social and Clinical Psychology, 9, 152-163.

McArthur, D., \& Adamson, L. B. (1996). Joint attention in preverbal children: Autism and developmental language disorder. Journal of Autism and Developmental Disorders, 26, 481-496.

Mead, G. H. (1934). Mind, self, and society from the standpoint of a social behaviorist. Chicago: University of Chicago Press.

Meltzoff, A. N. (1988). Infant imitation and memory: Nine-month-olds in immediate and deferred tests. Child Development, 59, 217-225.

Meltzoff, A. N., \& Brooks, R. (2001). "Like me" as a building block for understanding other minds: Bodily acts, attention, and intention. In B. F. Malle (Ed.), Intentions and intentionality: Foundations for social cognition (pp. 171-192). Cambridge, MA: MIT Press.

Meltzoff, A. N., \& Moore, M. K. (1997). Imitation of facial and manual gestures by human neonates. Science, 198, 75-78.

Meltzoff, A. N., \& Moore, M. K. (1998a). Infant intersubjectivity: Broadening the dialogue to include imitation, identity and intention. In S. Bråten (Ed.), Intersubjective communication and emotion in early ontogeny (pp. 47-62). Cambridge: Cambridge University Press.

Meltzoff, A. N., \& Moore, M. K. (1998b). Object representation, identity, and the paradox of early permanence. Infant Behavior and Development, 21, 200-236.

Meyer, J. A., \& Hobson, R. P. (2004). Orientation in relation to self and other: The case of autism. Interaction Studies, 5, 221-244.

Minshew, N. J., Meyer, J., \& Goldstein, G. (2002). Abstract reasoning in autism: A dissociation between concept identification and concept formation. Neuropsychology, 16, 327-334.

Morgan, S. B., Cutrer, P. S., Coplin, J. W., \& Rodrigue, J. R. (1989). Do autistic children differ from retarded and normal children in Piagetian sensorimotor functioning? Journal of Child Psychology and Psychiatry, 30, 857-864.

Moses, L. J., Baldwin, D. A., Rosicky, J. G., \& Tidball, G. (2001). Evidence for referential understanding in the emotions domain at twelve and eighteen months. Child Development, 72, 718-735.

Mundy, P. (1995). Joint attention and social-emotional approach behavior in children with autism. Development and Psychopathology, 7, 63-82.

Mundy, P. (2003). Annotation: The neural basis of social impairments in autism: The role of the dorsal medialfrontal cortex and anterior cingulate system. Journal of Child Psychology and Psychiatry, 44, 793-809.

Mundy, P., Kasari, C., \& Sigman, M. (1992). Nonverbal communication, affective sharing, and intersubjectivity. Infant Behavior and Development, 15, 377-381.

Mundy, P., \& Neal, R. (2001). Neural plasticity, joint attention, and a transactional social-orienting model of autism. International Review of Mental Retardation, 23, 139-168. 
Mundy, P., \& Sigman, M. (1989). The theoretical implications of joint-attention deficits in autism. Development and Psychopathology, 1, 173-183.

Mundy, P., Sigman, M. D., Ungerer, J., \& Sherman, T. (1986). Defining the social deficits of autism: The contribution of non-verbal communication measures. Journal of Child Psychology and Psychiatry, 27, $657-669$

Oberman, L. M., Hubbard, E. M., McCleery, J. P., Altschuler, E. L., Ramachandran, V. S., \& Pineda, J. A. (2005). EEG evidence for mirror neuron dysfunction in autism spectrum disorders. Cognitive Brain Research, 24, 190-198.

Ohta, M. (1987). Cognitive disorders of infantile autism: A study employing the WISC, spatial relationship conceptualisation, and gesture imitation. Journal of $\mathrm{Au}$ tism and Developmental Disorders, 17, 45-62.

Reddy, V., Williams, E., \& Vaughan, A. (2002). Sharing humour and laughter in autism and Down's syndrome. British Journal of Psychology, 93, 219-242.

Rheingold, H., Hay, D., \& West, M. (1976). Sharing in the second year of life. Child Development, 83 , 898-913.

Roeyers, H., Van Oost, P., \& Bothuyne, S. (1998). Immediate imitation and joint attention in young children with autism. Development and Psychopathology, 10, 441-450.

Rogers, S. J., Bennetto, L., McEvoy, R., \& Pennington, B. F. (1996). Imitation and pantomime in highfunctioning adolescents with autism spectrum disorders. Child Development, 67, 2060-2073.

Rogers, S. J., Hepburn, S. L., Stackhouse, T., \& Wehner, E. (2003). Imitation performance in toddlers with autism and those with other developmental disorders. Journal of Child Psychology and Psychiatry, 44, 763-781.

Russell, J., \& Jarrold, C. (1999). Memory for actions in children with autism: Self versus other. Cognitive Neuropsychiatry, 4, 303-331.

Schopler, E., Reichler, R. J., \& Renner, B. R. (1988). The Childhood Autism Rating Scale (CARS). Los Angeles: Western Psychological.

Seibert, J. M., Hogan, A. E., \& Mundy, P. C. (1982). Assessing interactional competencies: The Early Social Communication Scales. Infant Mental Health Journal, 3, 244-245.

Sigman, M. D., \& Capps, L. (1997). Children with autism: A developmental perspective. Cambridge, MA: Harvard University Press.

Sigman, M. D., Kasari, C., Kwon, J. H., \& Yirmiya, N. (1992). Responses to the negative emotions of others by autistic, mentally retarded, and normal children. Child Development, 63, 796-807.

Slaughter, V., \& McConnell, D. (2003). Emergence of joint attention: Relationships between gaze following, social referencing, imitation, and naming in infancy. The Journal of Genetic Psychology, 164, 54-71.

Smith, I. M., \& Bryson, S. E. (1998). Gesture imitation in autism I: Nonsymbolic postures and sequences. Cognitive Neuropsychology, 15, 747-770.

Sorce, J., Emde, R. N., Campos, J. J., \& Klinnert, M. (1985). Maternal emotional signalling: Its effect on the visual cliff behavior of 1-year-olds. Developmental Psychology, 21, 195-200.

Sroufe, L. A., \& Rutter, M. (1984). The domain of developmental psychopathology. Child Development, 55, $17-29$.

Stone, W. L., Ousley, O. Y., \& Littleford, C. D. (1997). Motor imitation in young children with autism: What's the object? Journal of Abnormal Child Psychology, $25,475-485$.

Striano, T., \& Rochat, P. (1999). Relation between dyadic and triadic social competence in 7- to 10-month-old infants. British Journal of Developmental Psychology, 17, 551-562.

Swettenham, J., Baron-Cohen, S., Charman, T., Cox, A., Baird, G., Drew, A., et al. (1998). The frequency and distribution of spontaneous attention shifts between social and non-social stimuli in autistic, typicallydeveloping, and non-autistic developmentally delayed infants. Journal of Child Psychology and Psychiatry, 39, 747-754.

Tomasello, M. (1995). Joint attention as social cognition. In C. Moore \& P. J. Dunham (Eds.), Joint attention: Its origins and role in development (pp. 103-130). Hillsdale, NJ: Erlbaum.

Tomasello, M. (1999). The cultural origins of human cog nition. Cambridge, MA: Harvard University Press.

Trevarthen, C., \& Hubley, P. (1978). Secondary intersubjectivity: Confidence, confiding and acts of meaning in the first year. In A. Lock (Ed.), Action, gesture, and symbol: The emergence of language (pp. 183-229). London: Academic Press.

Volkmar, F. R., \& Mayes, L. C. (1990). Gaze behavior in autism. Development and Psychopathology, 2, 61-69.

Werner, H., \& Kaplan, B. (1963). Symbol formation. Oxford: Wiley.

Wetherby, A. M., \& Prutting, C. A. (1984). Profiles of communicative and cognitive-social abilities in autistic children. Journal of Speech and Hearing Research, 27, 364-377.

Whiten, A., \& Brown, J. (1998). Imitation and the reading of other minds: Perspectives from the study of autism, normal children, and non-human primates. In S. Bråten (Ed.), Intersubjective communication and emotion in ontogeny: A sourcebook. Cambridge: Cambridge University Press

Williams, J. H. G., Whiten, A., Suddendorf, T., \& Perrett, D. I. (2001). Imitation, mirror neurons and autism. Neuroscience \& Biobehavioral Reviews, 25, 287-295.

Wimpory, D. C., Hobson, R. P., Williams, J. M. G., \& Nash, S. (2000). Are infants with autism socially engaged? A controlled study of recent retrospective parental reports. Journal of Autism and Developmental Disorders, 30, 525-536. 